\title{
Chromatin remodeler Fft3 plays a dual role at blocked DNA replication forks
}

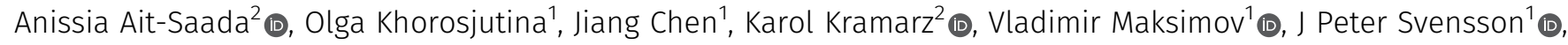 \\ Sarah Lambert ${ }^{2}$ (i), Karl Ekwall ${ }^{1}$ ]
}

\begin{abstract}
Here, we investigate the function of fission yeast Fun30/Smarcad1 family of SNF2 ATPase-dependent chromatin remodeling enzymes in DNA damage repair. There are three Fun30 homologues in fission yeast, Fft1, Fft2, and Fft3. We find that only Fft3 has a function in DNA repair and it is needed for single-strand annealing of an induced double-strand break. Furthermore, we use an inducible replication fork barrier system to show that Fft3 has two distinct roles at blocked DNA replication forks. First, Fft3 is needed for the resection of nascent strands, and second, it is required to restart the blocked forks. The latter function is independent of its ATPase activity.
\end{abstract}

DOI 10.26508/Isa.201900433 | Received 20 May 2019 | Revised 23 September 2019 | Accepted 24 September 2019 | Published online 1 October 2019

\section{Introduction}

In eukaryotic chromosomes, the DNA is packaged into chromatin fiber structures to allow for compaction of DNA in the nucleus and proper chromosome segregation in mitosis and meiosis. The basic unit of the chromatin fiber is the nucleosome consisting of $146 \mathrm{bp}$ of DNA wrapped around a protein structure of histones. Processes that need access to the DNA helix, for example, gene transcription, DNA replication, and repair are aided by nucleosome remodeling factors, which can disassemble or slide nucleosomes at a given genomic locus. SNF2 enzymes are ATP-dependent nucleosome remodeling factors with a conserved helicase-like domain (Flaus et al, 2006). Fun30 belongs to a subfamily of SNF2 enzymes with important roles in genome stability, gene regulation, and chromosome boundary function.

We and others have characterized the function of Fun30 homologues in fission yeast, Schizosaccharomyces pombe. There are three homologues called (Fission yeast Fun Thirty) Fft1, Fft2, and $\mathrm{Fft} 3$. Fft2 and $\mathrm{Fft} 3$ both have roles in regulation of expression and mobility of retrotransposable elements (Persson et al, 2016). Fft3 has functions at tRNA genes and LTR elements acting as chromosomal boundaries at centromeres and telomeres (Stralfors et al, 2011;
Steglich et al, 2015). Fft3 was recently implicated in transcription elongation by RNA polymerase II, where it is involved in disassembly and reassembly of nucleosomes to facilitate transcription (Lee et al, 2017). Another recent study found Fft3 in a genetic screen for factors needed for inheritance of heterochromatin at the silent mating-type loci. It was shown that Fft3 interacts with DNA replication factors (pol $\delta$ and $\varepsilon$ ) and is needed for proper DNA replication (Taneja et al, 2017). Moreover, Fft3 has also recently been identified by several high throughput genetic and proteomic screens in fission yeast. The first screen was monitoring silencing defects close to the domain boundary at the silent mating-type loci (Jahn et al, 2018). The second screen was identifying genes that interact with genes encoding Hamartin or Tuberin proteins involved in the human Tuberous sclerosis complex disorder, a benign tumor disease (Rayhan et al, 2018). Finally, Fft3 was identified by a proteomic screen for proteins bound to a meiotic recombination hotspot and was shown to be one of several chromatin regulators required for efficient recombination at the ade6-M26 hotspot (Storey et al, 2018).

Both in budding yeast, Saccharomyces cerevisiae, and in mammalian cells, Fun30 homologues have been implicated in DNA doublestrand break (DSB) repair, specifically in DNA end resection during homologous recombination (HR) (Chen et al, 2012; Costelloe et al, 2012; Eapen et al, 2012). The long-range 5' to 3' end resection, mediated by exonucleases such as Ex01, leads to long stretches of single-stranded DNA (ssDNA). Interestingly, a recent study found that these ssDNA structures may maintain association with histones, forming nucleosome-like structures, and Fun30 was effectively activated in vitro by such particles (Adkins et al, 2017). Short-range resection mediated by Exo1 and Fun30 was recently implicated in facilitating the mismatch DNA repair process (Goellner et al, 2018). Consistent with this notion, the Xenopus Fun30 homologue Smarcad1 was recently shown to facilitate nucleosome exclusion during mismatch repair (MMR) (Terui et al, 2018). Thus, Fun30 and its Smarcad1 homologue have established roles in resection during DNA repair processes.

Here, we have investigated the function of the three Fun30 homologues Fft1, Fft2, and Fft3 in S. pombe DNA damage repair. Two of the homologues, Fft1 and Fft2, do not seem to be involved in DNA repair. In contrast, the third homologue, $\mathrm{Fft}$, is important for

${ }^{1}$ Department of Biosciences and Nutrition, Karolinska Institutet, Huddinge, Sweden $\quad{ }^{2}$ Institut Curie, Paris-Saclay University, Centre National de la Recherche Scientifique, Unités Mixtes de Recherche 3348, F-91405, Orsay, France

Correspondence: Sarah.Lambert@curie.fr; karl.ekwall@ki.se 
DNA repair and cells lacking Fft3 are sensitive to several DNAdamaging drugs. A series of experiments have revealed a role for Fft3 in promoting single-strand annealing (SSA) and HR-mediated replication fork restart. We have uncovered a dual role for $\mathrm{Fft} 3$ at the stalled replication forks. Fork resection is dependent of the ATPase activity of Fft3, whereas the subsequent step of fork restart is facilitated by $\mathrm{Fft} 3$ but is independent of its ATPase activity.

\section{Results}

\section{The Fft3 $\Delta$ mutant has a defect in SSA}

To test if any of the S. pombe Fun30 genes are involved in repair of DNA damage, we performed growth assays on plates containing the DNA-alkylating agent methyl methanesulfonate (MMS) that induces damaged replication forks. MMS alkylates guanine and adenine to cause mispairing and replication block. In the repair process, SSDNA breaks and gaps are produced, serving as a substrate for HR. S. pombe strains harboring gene knockouts for fft $1 \Delta, f f t 2 \Delta, f f t 3 \Delta$, and wild-type control were serially diluted and spotted onto YES plates with 0.005 and $0.01 \%$ MMS (Fig 1A). After $4 \mathrm{~d}$ of incubation at $30^{\circ} \mathrm{C}$, only one of the mutants, fft $3 \Delta$, displayed increased MMS sensitivity as compared with wild-type control, in accordance with the recent report from Taneja et al, (2017).

To investigate the mechanistic role of $\mathrm{Fft} 3$ in DNA damage repair, we used an assay for resection of a single DSB (Watson et al, 2011). This system (HOcs-SSA) is based on the MATa HO-endonuclease cutting site placed into the his $3^{+}$gene flanked by a disrupted $\mathrm{S}$. cerevisiae LEU2 marker gene $\sim 5 \mathrm{~kb}$ away on each side (Fig 1B). Upon $\mathrm{HO}$ induction by addition of uracil to activate urg1-HO, DSBs are generated. The disrupted LEU2 marker gene has a stretch of homologous sequence, allowing the SSA process of DSB repair to occur. Effective SSA results in a functional LEU2 allele accompanied by the loss of the his $3^{+}$gene. Induction of the DSB but failure to complete the SSA pathway will result in the loss of the his $3^{+}$marker and LEU2 gene. The his3 ${ }^{+}$gene could also be lost by processing of the DSB through other repair pathways including nonhomologous end joining (NHEJ), as NHEJ will generally induce a frameshift. The $f f t 1 \Delta, f f t 2 \Delta$, and $f f t 3 \Delta$ mutations were introduced in this model. As a positive control, we used a strain harboring a gene deletion for the Exo1 exonuclease required for the resection of DSBS and SSA products. After DSB induction, the colonies were allowed to form on nonselective media. To compensate for differences in growth rates, fft $1 \Delta$ and $f f t 2 \Delta$ mutants were grown for $5 \mathrm{~d}$ and, whereas the slower $f f t 3 \Delta$ was grown for $7 \mathrm{~d}$. After this incubation, the plates were replica-plated to the media lacking histidine and/or leucine and incubated for two additional days continuously. After this selection, the number of $\mathrm{His}^{-} \mathrm{Leu}^{+}$, $\mathrm{His}^{-} \mathrm{Leu}^{-}$, and $\mathrm{His}^{+} \mathrm{Leu}^{-}$colonies was quantified (Fig 1C). Cell viability after $\mathrm{HO}$ induction was interpreted as completed DSB repair. The only mutants that displayed decreased DSB repair were fft3 $\triangle$ and ex01 $\Delta$. The LEU2-interspersed sequence of $16 \mathrm{His}^{-}$Leu $^{-}$colonies was sequenced ( 11 from fft3 $\Delta$ and 5 from exo1 $\Delta$ ), expecting NHEJ products. However, NHEJ products were not found. Instead, all fft3 $\Delta$ clones had the sequence expected from SSA processing, but for unknown reason, these clones had not grown on the media lacking leucine. Possible explanations include that the breaks were repaired slower resulting in a delay in colony formation, or epigenetic silencing of the LEU2 locus.

Next, we measured the induction of DSB at the his $3^{+}$gene in wildtype, fft2 $\Delta$, and fft3 $\Delta$ cells by qPCR (Fig S1). We observed an approximately twofold reduction of DSB in fft $3 \Delta$ cells after $5 \mathrm{~h}$ that could contribute to a delay in the SSA process. To directly test the possibility of a delayed SSA repair, we then measured the appearance of the restored $L E U 2$ gene by qPCR at different time points after $\mathrm{HO}$ induction. To control for the observed different efficiencies of DSB induction, we normalized the data to evaluate only the cells where a DSB had occurred and followed the kinetics of repair by SSA (Fig 1D). We found that in fft3 $\triangle$ cells, the appearance of SSA products was indeed delayed, whereas in fft2 $\Delta$ cells, SSA products appeared with similar kinetics as in the wild type. Thus, no defect in DSB induction or SSA kinetics was detected in fft2 $\triangle$. In contrast, the fft3 $\triangle$ mutant had a clear defect in both the DSB induction and the kinetics of repair by SSA. Hence, we conclude that unlike its paralogues $\mathrm{Fft} 1$ and $\mathrm{Fft} 2, \mathrm{Fft} 3$ plays a role in promoting SSA.

\section{The ATPase domain of Fft3 is needed for cell resistance to replication stress}

Fft3 is an ATPase enzyme and the ATPase domain is essential for its nucleosome remodeling catalytic activity used for nucleosome remodeling. To test if the catalytic activity of $\mathrm{Fft} 3$ is needed for its function in DNA repair, we performed growth assays on plates containing a panel of DNA-damaging agents. This panel included MMS; camptothecin (CPT), an inhibitor of topoisomerase I inducing replication forks impediments; hydroxyurea (HU), an inhibitor of the ribonucleotide reductase inducing a global replication fork slow down and stalling; and bleomycin (Bleo), a DSB-inducing drug. S. pombe strains with epitope-tagged fft3-myc, the epitope-tagged ATPase-deficient allele fft3-K418R-myc, carrying a gene deletion $f f t 3 \Delta$, and a control strain deleted for the recombinase Rad51, rad51 $\triangle$, were serially diluted and spotted onto YES plates with different concentrations of the agents (Fig S2). The fft3-K418R-myc strain exhibited similar sensitivity to CPT and MMS than fft $3 \triangle$ cells, indicating that the ATPase activity is required to promote cell resistance to replication stress. No increased sensitivity to Bleo was observed in cells lacking Fft3 or only its ATPase activity in contrast to rad51 $\triangle$. This indicates that Fft3, in spite of its role in DSB repair by SSA, is largely dispensable to promote survival after DSB induction. In contrast to a previous report (Taneja et al, 2017), we found that $f f t 3 \Delta$ and fft3-myc cells were not sensitive to HU treatment, whereas fft3-K418R-myc cells showed a slightly higher sensitivity to $\mathrm{HU}$ treatment. These data reveal that, under specific circumstances, the lack of the ATPase activity of Fft3 can be more toxic than the lack of the protein itself, further supporting the importance of the ATPase activity of Fft3 to promote cell resistance to replication stress.

\section{Fft3 is needed for efficient DNA resection at blocked replication fork}

To assess the mechanistic roles of $\mathrm{Fft} 3$ in the process of stressed replication forks, we have used the conditional RTS1-replication 
A

WT

$f f 1 \Delta$

$f f 2 \Delta$

$f f t 3 \Delta$ $30^{\circ} \mathrm{C}$, YES

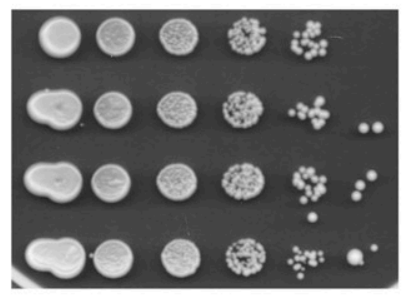

$30^{\circ} \mathrm{C}, 0.005 \% \mathrm{MMS}$

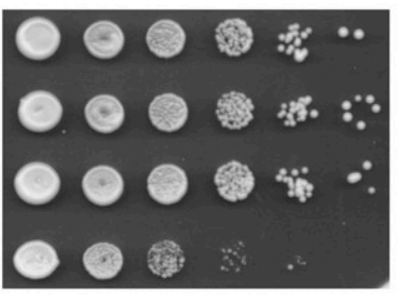

$30^{\circ} \mathrm{C}, 0.01 \% \mathrm{MMS}$

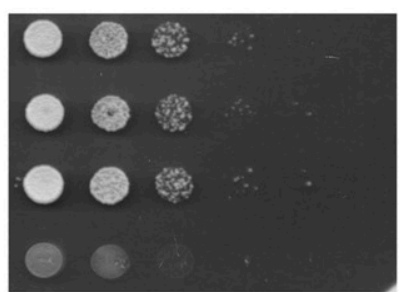

B

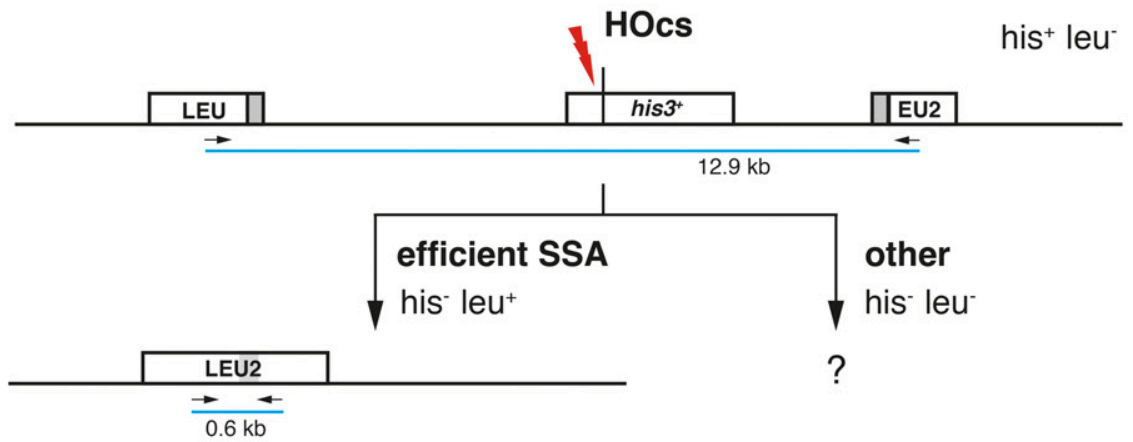

C
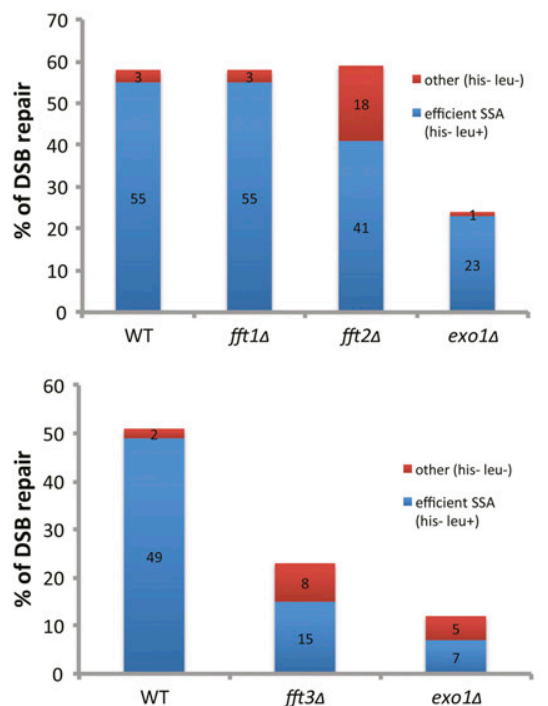
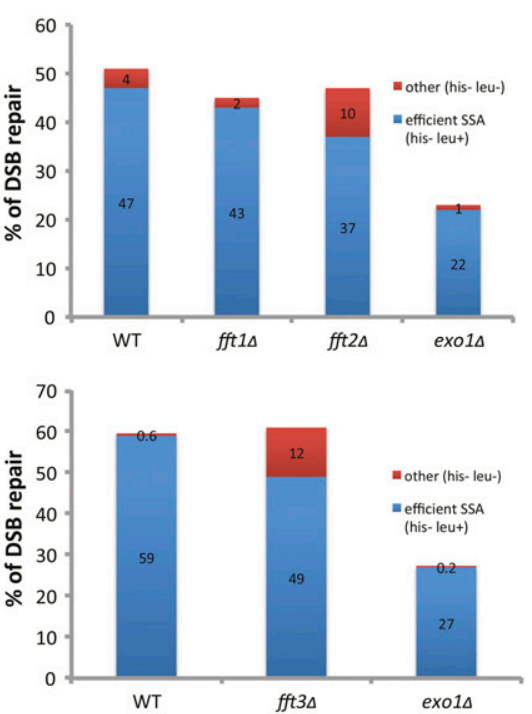

D

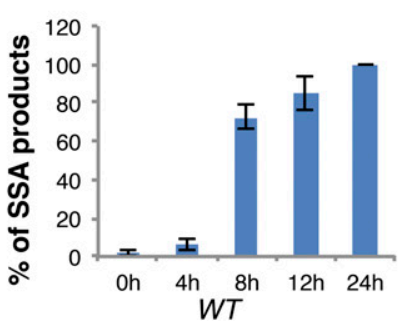

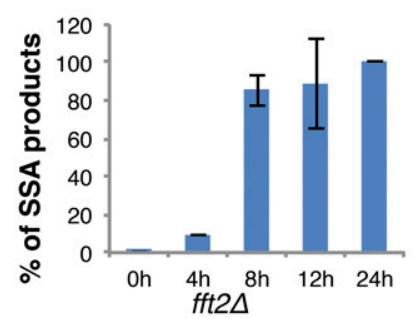

fork barrier (RFB) that allows a single replisome to be blocked in a polar manner at a specific locus (Fig 2A). The RTS1-RFB is encoded by the RTS1 DNA sequence bound by the protein Rtf1, the expression of which is regulated by the thiamine-repressible nmt41 promoter

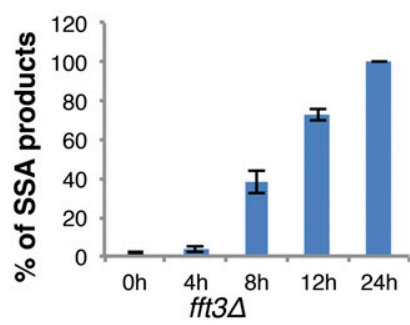

(Lambert et al, 2005). Upon expression of Rtf1, $>90 \%$ of forks travelling in the main replication direction away from the centromere become arrested and dysfunctional at the RTS1-RFB (Lambert et al, 2010). Arrested forks are either rescued by a
Figure 1. Fft3 has a role in DNA damage repair and promotes SSA.

(A) Spotting assays using DNAdamaging drugs. Photographs of YES plates after 4 -d incubation at $30^{\circ} \mathrm{C}$ containing MMS at different concentrations (as indicated). The strain used were Hu0029 (WT), Hu2656 (fft1 $\Delta$ ), Hu1673 (fft2 $\Delta$ ), and Hu1309 (fft3A). (B) Schematic diagram of SSA assay from Watson et al (2011). $\mathrm{His}^{-}$Leu $^{+}$colonies represent completed SSA events and $\mathrm{His}^{-}$Leu colonies represent other repair events. Primers for quantitative PCR (arrows) and distances between them at the different genotypes are indicated. (C) Bar diagrams showing the percentage of DSB repair as viability after DSB induction in WT and the four mutants. Blue bars represent repair by SSA (interpreted by his $^{-}$leu ${ }^{+}$ phenotype) and red bars represent other repair (viable colonies with his ${ }^{-}$ leu ${ }^{-}$phenotype). Processing after DSB induction on nonselective media was allowed for 5-7 d before phenotype testing $(n=2)$. (D) Bar diagrams showing the kinetics of SSA products after DSB induction, relative to the level at $24 \mathrm{~h}$. The SSA product is estimated by quantitative PCR over the LEU2 locus capturing the $44 \mathrm{bp}$ product ( $n=3$, error bars show SD). For panels (B) and (C) the strains used were Hu2694, Hu2695, Hu2697, and Hu2698. 
A

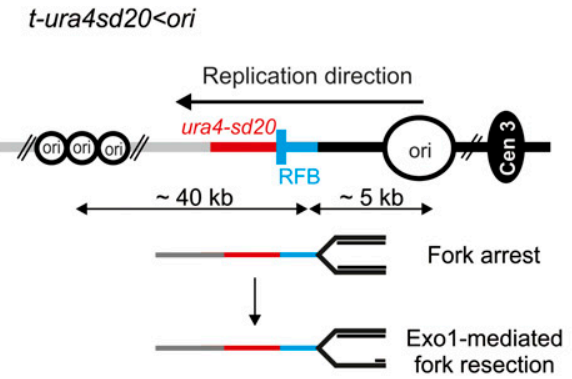

D

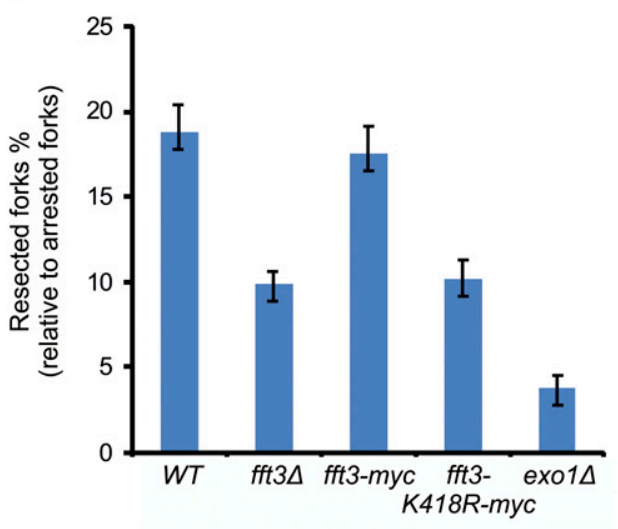

E

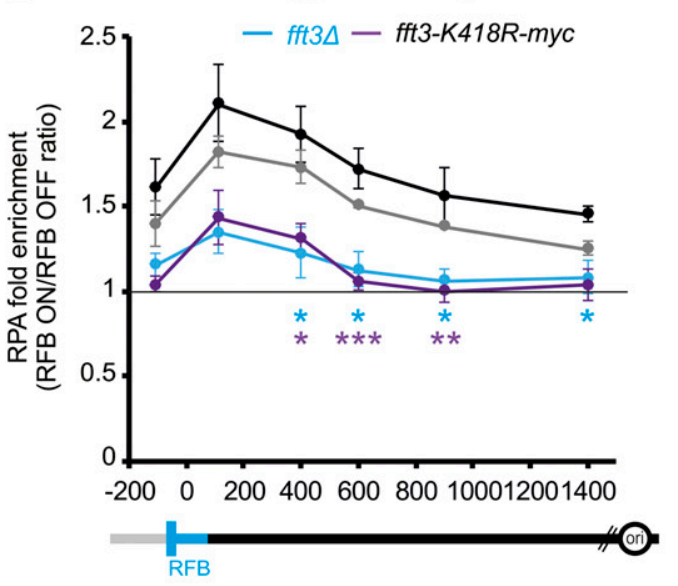

B

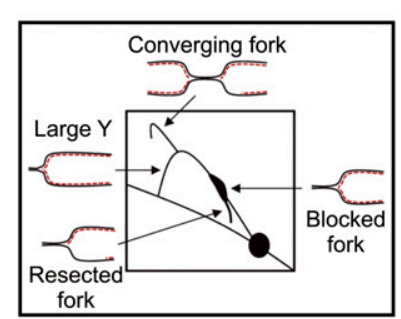

C
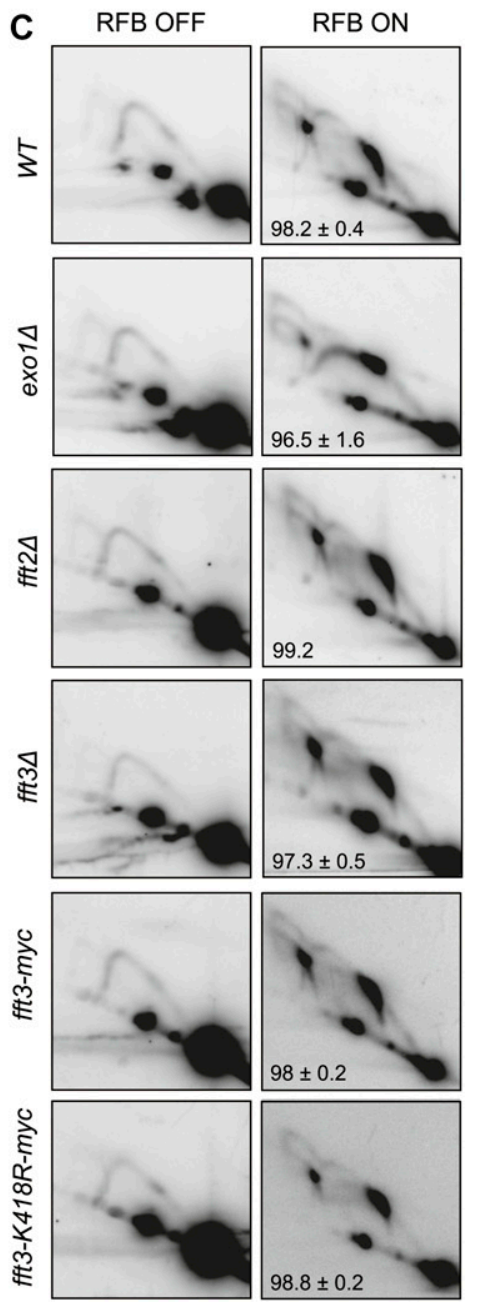
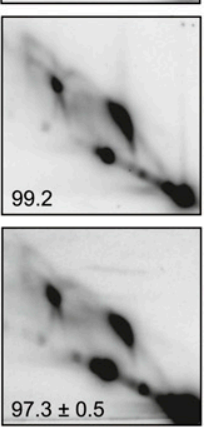

RFB ON

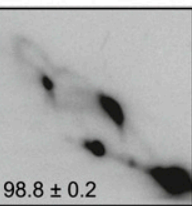

Figure 2. Fft3 promotes DNA end resection at arrested forks through its ATPase activity.

(A) Diagram of the t-ura4sd20<ori construct, on chromosome 3, containing a single RTS1-RFB ( $<$ and blue bars) blocking replication forks travelling in the main replication direction. Main replication origins (ori, black circles) located upstream and downstream of the RTS1-RFB are indicated with their respective distances from the RFB. When Rtf1 is expressed, > $90 \%$ of forks emanating from the strong centromereproximal replication origin, and moving towards the telomere, are blocked. HR-mediated fork restart is initiated through the generation of a 1-kb-sized SSDNA gap in an Exo1-dependent manner. (B) Scheme of replication intermediates (RIS) observed in a neutral-neutral 2DGE analysis of the Asel restriction fragment upon activation of the RTS1-RFB.

(C) Representative RI analysis by 2DGE in the absence (RFB OFF) or presence of fork blockade (RFB ON) in indicated strains. A DNA fragment corresponding to ura 4 gene was used as probe. For each strain, numbers indicate the efficiency of the RFB; values are means of at least three independent experiments \pm SD.

(D) Quantification of \% of fork undergoing resection (tail signals) relative to the number of blocked forks. Values are means of at least three independent experiments \pm the $95 \%$ confidence interval $(99 \% \mathrm{Cl})$. In panels (C) and (D), the strains used were YC13 (WT), YC281 (fft3 $\Delta$ ), YC287 (fft2 $\Delta$ ), YC309 (fft3-myc), and YC313 (fft3-K418R-myc). (E) Binding of RPA (Ssb3-YFP) to the RTS1-RFB in indicated strains. ChIP-qPCR results are presented as an ON/OFF ratio for each strain. Upstream and downstream distances from the RFB are indicated in bp. Values are mean of four independent experiments \pm SEM. $P$ values were calculated using unpaired $t$ test $\left({ }^{* *} P \leq 0.001 ;{ }^{* *} P \leq 0.01 ;{ }^{*} P \leq 0.05\right)$. Data from $f f t 3 \Delta$ (KK854 strain) were compared with wild-type (KK851 strain) (blue stars) and data from fft3-K418Rmyc (KK857 strain) were compared with fft3-myc strain (KK860 strain) (purple starts). converging fork or restarted by the HR pathway. HR-mediated fork restart occurs in 20 min through the generation of an SSDNA gap, which is subsequently coated by the Rad51 recombinase, with the help of its loader Rad52 (Tsang et al, 2014; Miyabe et al, 2015). After Rad51-mediated strand invasion of the parental duplex, the resumption of DNA synthesis occurs at the site of the arrested fork.

The generation of 1-kb-sized ssDNA gap at the active RTS1-RFB includes the resection of newly replicated strands by the nuclease Exo1 (Fig 2A) (Tsang et al, 2014, Ait Saada et al, 2017, Teixeira-Silva et al, 2017). The step of fork resection can be monitored by analyzing replication intermediates by two-dimensional gel electrophoresis (2DGE). We have previously reported a novel replication intermediate, emanating from blocked forks and descending toward the linear arc, corresponding to arrested forks in which newly replicated strands undergo Ex01-mediated end resection (Fig 2B) (Ait Saada et al, 2017). Consistent with this, the "tail signal" was nearly completely lost in exo1 $1 \Delta$ cells (Fig 2 C and D), as previously reported (Ait Saada et al, 2017). We found that fork resection was impaired in fft $3 \Delta$ cells but not in fft2 $\Delta$ cells. Quantification of the tail signal revealed a twofold reduction of the level of fork resection in fft $3 \Delta$ cells compared with wild-type cells (Fig $2 C$ and D). To test if the role of Fft3 in promoting fork resection requires its ATPase activity, we analyzed the ATPase-deficient allele Fft3-K418R (Steglich et al, 2015). We found a similar decrease in the level of resected forks as 
observed in the null mutant (Fig $2 \mathrm{C}$ and D). Of note, the fusion of a myc-tag to Fft3 has no impact on fork resection, further supporting that Fft3-myc is functional as suggested by the insensitivity of the strain to genotoxic drugs (Fig S2). To further support the role of Fft3 and its ATPase activity in promoting end resection at arrested forks, we have used an alternative assay by analyzing the recruitment of Ssb3-YFP, one subunit of the SSDNA-binding protein RPA, to the RST1-RFB. The binding of RPA upstream from the RTS1-RFB is dependent on nucleases such as Mre11 and Exo1 and, thus, reflects the formation of ssDNA (Tsang et al, 2014). The recruitment of RPA upstream from the RTS1-RFB was significantly reduced in fft $3 \triangle$ cells and in cells expressing Fft3-K148R (Fig 2E). This was particularly pronounced from $400 \mathrm{bp}$ and more behind the arrested fork, indicating a less efficient long-range resection. We concluded that Fft3 and its chromatin remodeling activity promote the Exo1mediated long-range resection of nascent strands at arrested forks.

\section{Chromatin-binding analysis at blocked DNA replication forks}

To determine if Fft3 has a direct effect at blocked DNA replication forks, we performed ChIP of Fft3-myc-tagged cells and tested occupancy in the RTS1-RFB ura4 L5 region (Fig 3A). We compared occupancy of Fft3-myc in RFB on and RFB off conditions using \pm thiamine in the growth media. As a positive control, we used the valine tRNA gene known to be the site of Fft3 binding (Steglich et al, 2015). It was clear that binding occurred to $L 5$ both in RFB on and off conditions at similar magnitude to valine tRNA genes (Fig 3B and C). In addition, the ATPase-deficient allele fft3-K418R-myc also showed binding to $L 5$, regardless of the activity of the RFB, indicating that the fork resection defect observed in this mutant is not caused by an inability to bind the chromatin near the RFB. Nonetheless, the data obtained suggest that Fft3 is constitutively bound to the chromatin in the vicinity of the RFB regardless of its activity. To test this, we used another construct, t-ura4sd20-ori, devoid of the RTS1 sequence (Fig 3D and E). We observed that Fft3-myc bound to L5 at similar magnitude to valine tRNA genes, irrespective of the media condition (with or without thiamine). We concluded that Fft3 is constitutively bound to the chromatin at the ura 4 locus, regardless of the activity of the RFB, preventing us to directly assess its specific recruitment to blocked replication forks.

\section{Fft3 is needed for efficient DNA replication restart at blocked replication fork}

HR-mediated fork restart at the RTS1-RFB results in a restarted replisome, which is mechanistically distinct from a canonical replisome, with DNA polymerase $\delta$ synthetizing both strands (Miyabe et al, 2015). Restarted replisomes are error-prone, associated with a DNA synthesis intrinsically prone to replication slippage (RS) at regions of micro-homology (Iraqui et al, 2012; Mizuno et al, 2013) (Fig 4A). We have previously developed genetic assays to monitor the RS frequency occurring as a consequence of progression of the restarted replisome. The nonfunctional ura4sd20 allele, containing a 20-nt duplication flanked by micro-homology, was integrated either upstream or downstream of the RTS1-RFB (Fig 4B). When the ura4sd20 allele is replicated by a restarted replisome, the propensity of DNA polymerase to undergo RS allows the duplication to be deleted. In this manner, a functional ura4 ${ }^{+}$gene is restored and $\mathrm{Ura}^{+}$cells are generated. As a consequence of newly replicated strands undergoing end resection, restarted replisomes occasionally initiate upstream from the RTS1-RFB (Fig 4A). As control, a construct containing the reporter ura4sd20 allele and devoid of the RTS1-RFB is used to monitor the frequency of spontaneous Ura ${ }^{+}$cells in each genetic background (Fig 4B). Upon activation of the RTS1-RFB, the frequency of upstream RS was induced by $~ 2.6$-fold in wild-type, fft2 $\Delta$, and fft3-myc strains, whereas no significant increase was observed in fft3 $\Delta$ and fft3-K418Rmyc strains (Fig 4C). These data are consistent with the step of fork resection being dependent on $\mathrm{Fft} 3$ and its ATPase activity, but not Fft2.

Upon activation of the RTS1-RFB, the frequency of downstream RS was induced by 15 -fold in wild-type and fft $2 \Delta$ cells and by only approximately fourfold in fft3 $\Delta$ cells (Fig 4D, top panel), indicating that only one-third of forks arrested at the RTS1-RFB are efficiently restarted in the absence of $\mathrm{Fft} 3$. Surprisingly, the induction of downstream RS in fft3-K418R-myc strain was similar to the one observed in wild-type cells (Fig 4D, bottom panel). This finding indicates that the lack of the ATPase activity does not impact the efficiency of HR-mediated fork restart. Collectively, these data establish a role for Fft3 in ensuring efficient HR-mediating fork restart, independently of its ATPase activity and its role in promoting fork resection.

\section{Discussion}

\section{A role for $\mathrm{Ff3}$ in DNA damage repair processes}

Our work shows that of three Fun30 homologues, only Fft3 is implicated in the DNA damage repair in S. pombe. We show that Fft3 is required for proper SSA and processing of arrested replication forks. Both these processes depend on DNA resection requiring the ATPase domain and, hence, the nucleosome remodeling activity of Fft3. Similarly, Fun30 stimulates the long-range resection of DSBS but is dispensable for the initial resection (Chen et al, 2012; Costelloe et al, 2012; Bantele et al, 2017). The overexpression of Exo1 is sufficient to restore cell resistance of cells deleted for Fun30 to genotoxic drugs (Bi et al, 2015). Altogether, these data indicate an evolutionarily conserved function for $\mathrm{Fft} 3$ in promoting the Exo1mediated long-range resection both at DSBs and blocked replication forks via its nucleosome remodeling activity. It is possible that $\mathrm{Fft} 3$ is also involved in MMR in S. pombe because $\mathrm{Fft} 3$ has been found to interact with the MMR protein Msh2 (Lee et al, 2017). In budding yeast, MMR depends on Fun30 activity and it is thought that the MMR process also requires DNA resection facilitated by Fun30 (Goellner et al, 2018).

\section{Several different functions of Fft3 in the nucleus}

In addition to its role in DNA repair described here, Fft3 has previously been implicated in the chromosome domain organization of centromeres and telomeres by affecting LTR boundaries and tRNA boundaries (Stralfors et al, 2011; Steglich et al, 2015). A function of $\mathrm{Fft} 3$ in replication and propagation of heterochromatin has been shown by Taneja et al (2017) and Fft3 has been reported to be 
A t-ura4-sd20<ori

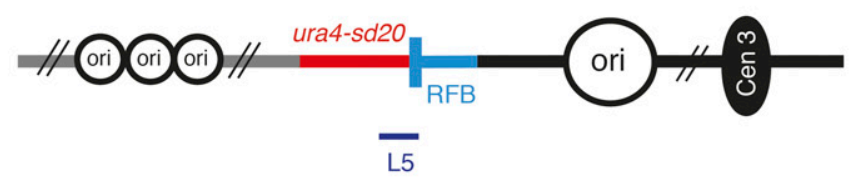

B

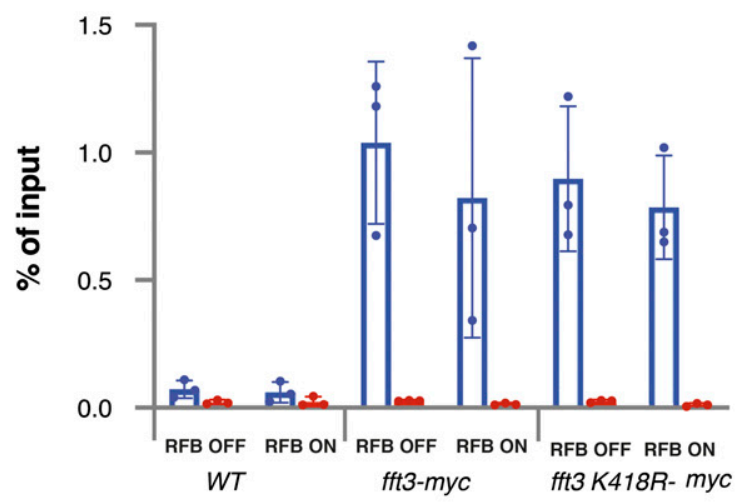

C

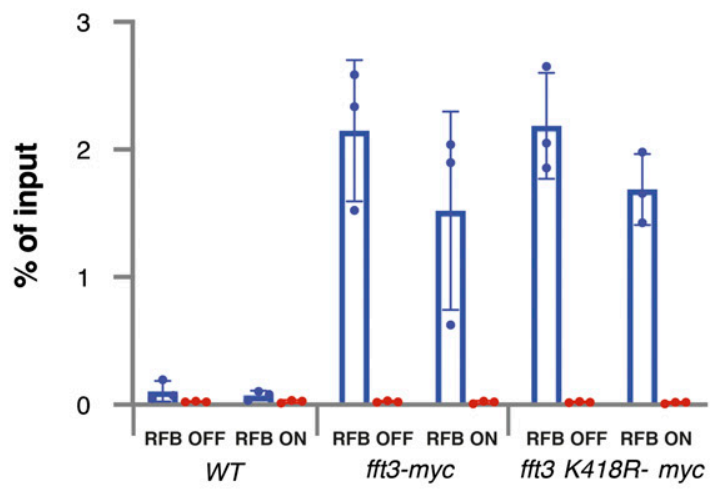

D t-ura4-sd20-ori

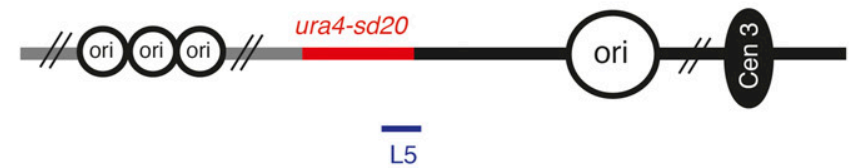

E

- L5

- tRNA

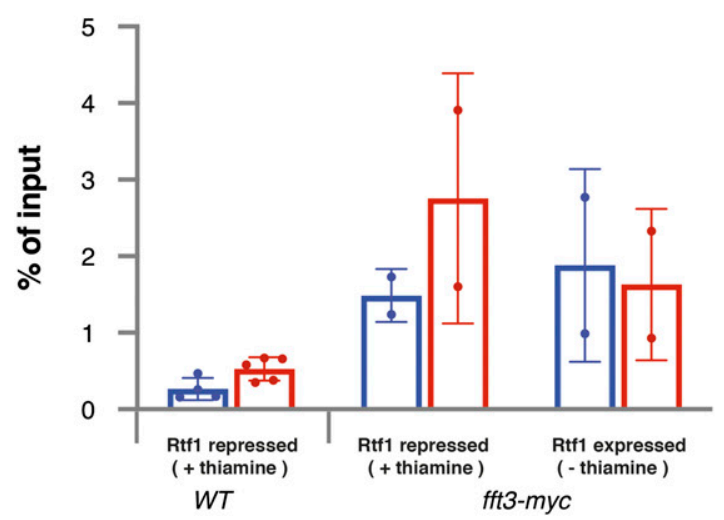

Figure 3. Fft3 is associated with chromatin at the ura4 locus independently of the RFB.

(A) Schematic diagram of $t$-ura4sd20<ori construct. The thick bar indicates position of PCR product at the ura4 locus (L5) to detect Fft3-myc. (B) Fft3 recruitment to RTS1-

RFB (L5) in indicated strains and conditions. Data from ChIP-qPCR of non-tagged wild-type, Fft3-myc, and Fft3-K418R-myc are shown. Enrichment is quantified as fraction of input. Error bars represent SD from three biological replicates. (C) Fft3 recruitment to valine tRNA genes. (B) Data and error bars as in (B). (D) Schematic diagram of t-ura4sd20-ori construct. (E) Fft3 recruitment to the ura4 locus. The thick bar indicates position of PCR product at the ura4 locus (L5) to detect Fft3-myc. In panels (B) and (C), the strains used were YC13 (WT), YC309 (fft3-myc), and YC313 (fft3-K418R-myc). In panel (E), strains used were YC13 (WT) and YC321 (fft3-myc). 
A

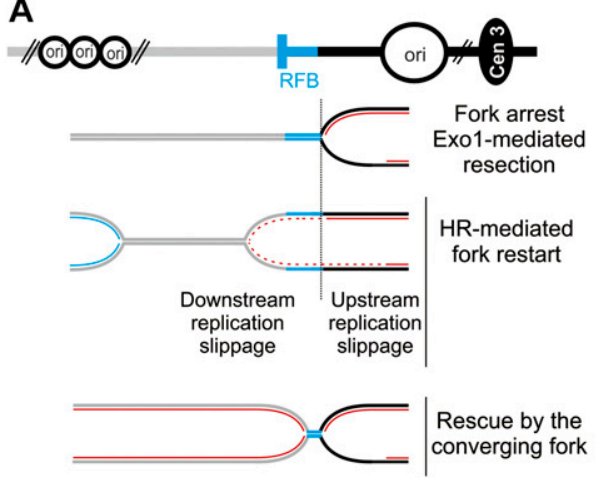

Canonical DNA synthesis
Non-processive DNA synthesis liable to replication slippage
C
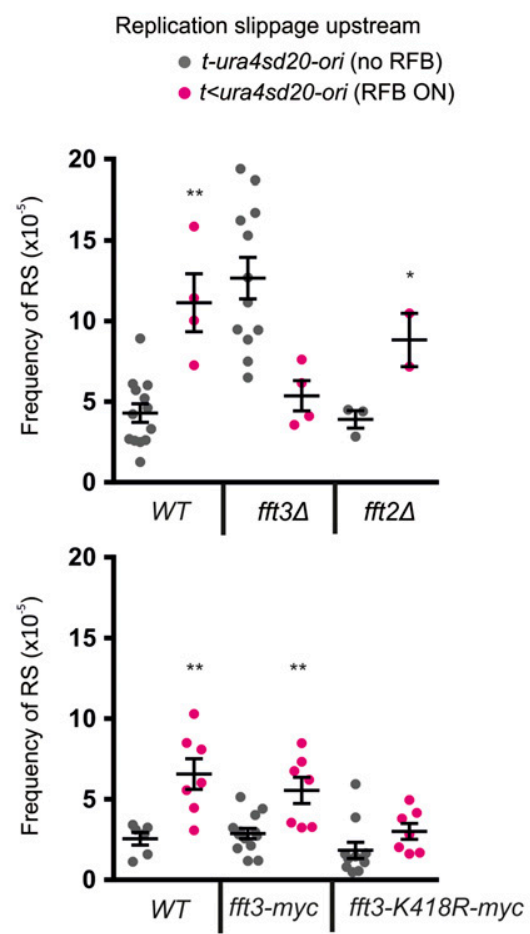

B

t-ura4sd20-ori : basal replication slippage

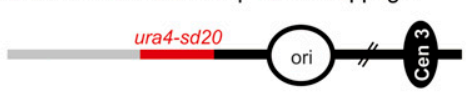

t-ura4sd20<ori : replication slippage downstream

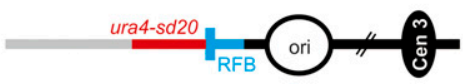

$t<u r a 4 s d 20$-ori : replication slippage upstream

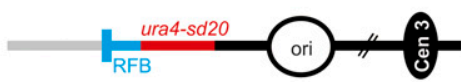

Figure 4. Fft3 promotes replication fork restart independently of its ATPase activity.

(A) Scheme of non-processive DNA synthesis

associated to forks restarted at the RTS1-RFB (blue bar).

Main replication origins (ori, black circles) located upstream and downstream of the RTS1-RFB are indicated. HR-mediated fork restart results in the progression of a restarted replisome associated to a non-processive DNA synthesis liable to RS (dotted red lines). Non-processive DNA synthesis can extend upstream of the RTS1-RFB as a consequence of fork resection. (B) Diagrams of constructs containing the reporter gene ura4-sd20: either not associated with the RTS1-RFB (top construct) or located downstream or upstream of the RTS1-RFB (middle and bottom constructs, respectively). The ura4-sd20 allele contains a 20-nt duplication flanked by microhomology. When replicated by a restarted replisome, the associated non-processive DNA synthesis commits RS, allowing the duplication to be deleted and, thus, restoring a functional ura 4 gene and generating Ura+ cells. (C) Frequency of upstream RS (Ura+ cells) in indicated strains and conditions. The frequency of RS with the t<ura4sd20-ori was monitored upon Rtf1 expression (RFB ON). The construct $t$ - $u$ ra4sd20-ori, devoid of RFB, was used as control to monitor the basal frequency of RS upon expression of Rtf1 (no RFB). Each dot represents one sample. Bars indicate mean values \pm SEM. Statistical analysis was performed using $t$ test (*P<0.04, $\left.{ }^{* *} P<0.004\right)$. (D) Frequency of downstream RS (Ura+ cells) in indicated strains and conditions. The frequency of RS with the $t$-ura $4 s d 20<0$ ori was monitored upon Rtf1 expression (RFB ON). The construct $t$-ura4sd20-ori, devoid of RFB, was used as control to monitor the basal frequency of RS upon expression of Rtf1 (no RFB). Each dot represents one sample. Bars indicate mean values \pm SEM. Statistical analysis was performed using $t$ test $\left({ }^{\star} P<0.04,{ }^{* *} P<\right.$ 0.004). In panels (C) and (D), strains used were YC6, YC13, and YC21 for WT; YC280, YC281, and YC292 for fft3 YC284, YC287, and YC294 for fft2A; YC321, YC309, and YC317 for fft3-myc; and YC329, YC313, and YC325 for fft3K418R-myc.

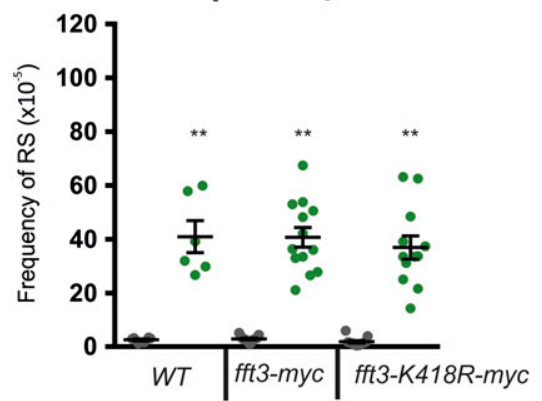

required for silencing near the silent mating type heterochromatin domain boundary (Jahn et al, 2018). It is also involved in the control of gene expression (Lee et al, 2017). Finally, Fft3 is implicated in the repression of Tf2 expression and mobility (Persson et al, 2016). Thus, $\mathrm{Fft} 3$ is a key enzyme with multiple tasks in the nucleus.

\section{Mechanism of Fft3 function during DNA replication}

Fft3 is an SNF2 helicase with a conserved ATPase domain belonging to the Fun30/Smarcad1 subfamily. This subfamily of SNF2 enzymes has previously been implicated both in nucleosome assembly and disassembly processes. In S. pombe, there is evidence for $\mathrm{Fft} 3$ carrying out both processes, for example, at Tf2 elements, a key regulatory nucleosome in the $5^{\prime}$ LTR is stabilized by Fft3. This stabilization leads to repression of Tf2 expression (Persson et al,
2016). In gene-coding regions, Fft3 contributes to nucleosome disassembly (Lee et al, 2017) and in the silent mating type region to nucleosome assembly, and roles in DNA replication, epigenetic inheritance, and suppression of nucleosome turnover have been demonstrated (Taneja et al, 2017). In other species, Fun30 and Smarcad1 play a role in nucleosome disassembly during DNA resection (Chen et al, 2012; Costelloe et al, 2012; Eapen et al, 2012). It is, therefore, likely that nucleosome disassembly is the relevant mechanism operating during DNA resection at blocked forks in fission yeast. This notion is consistent with the requirement of the ATPase domain of $\mathrm{Fft} 3$ for this function and the observation that single-stranded regions generated during resection have been shown as preferred substrate for Fun30 ATPase activity in vitro (Adkins et al, 2017). It is plausible that Fft3 maintains nucleosomefree regions promoting Exo1 activity during long-range resection 
allowing for rescue of blocked forks by HR. It has been proposed that Fft3 precludes nucleosomes turnover to prevent the formation of natural fork obstacles, such as co-transcriptional R-loops, at highly transcribed genes, short repeats, and tRNAs (Taneja et al, 2017). In the absence of $\mathrm{Fft} 3$, replication defect occurs across various euchromatic loci. Here, we report novel functions by which $\mathrm{Fft} 3$ facilitates replication fork progression. First, $\mathrm{Fft} 3$ promotes the processing of arrested forks via its nucleosome remodeling activity. Second, Fft3 fine-tunes HR-mediated fork restart independently of its ATPase activity. Thus, Fft3 acts as a chromatin organizer to facilitate replication fork progression but also via an additional function unrelated to nucleosome remodeling. Regarding the ATPase-independent function of $\mathrm{Fft} 3$ in fork restart, a second mechanistic role of $\mathrm{Fft} 3$ is conceivable, perhaps involving the observed interactions with the DNA replication machinery (Taneja et al, 2017).

\section{Blocked forks and effects on Tf2 mobility}

We previously showed that $\mathrm{Fft} 3$ is required to prevent mobility of the Tf2 class of retrotransposons in fission yeast (Persson et al, 2016). It is likely that this is a combined effect of reducing the expression of Tf2 and reducing the exposure of its possible insertion regions. Blocked DNA replication forks are known to be hot spots of Tf2 insertion (Jacobs et al, 2015). In fft3 $\Delta$ cells, the number of stalled forks is expected to increase because the mechanism of fork processing and restart are impaired. It remains to be tested if Fun30 and Smarcad1 homologues have a conserved function in repression of transposon mobility.

\section{Genomic protection by Fft3 linked to its role in controlling nuclear organization?}

Genome-wide mapping of Fft3-myc occupancy demonstrated enrichments at replication origins and several DNA repeat regions, including LTR elements and loci encoding tRNA, snoRNA, snRNA, and ncRNA (Steglich et al, 2015). DNA repeats are challenging for the DNA replication machinery and often cause impediments to fork progression. It is, therefore, tempting to speculate that Fft3 plays a general role in genome protection against DNA damage by its localization to these regions. A long-range DNA resection mechanism may be required at these loci to prevent unwanted recombination events between repeats when blocked forks are rescued by HR. Interestingly, some of these repeat elements also serve as chromatin domain boundaries (Allshire \& Ekwall, 2015). We hypothesize that the protection of chromosomal regulatory domains and higher order chromatin domain structure by Fft3 could be linked to its role in homology-driven DNA damage repair.

\section{Materials and Methods}

\section{S. pombe strains and growth conditions}

The S. pombe strains used in this study are listed in Table 1. We used standard growth conditions and protocols for genetic experiments (Petersen \& Russell, 2016; Ekwall \& Thon, 2017). Strains carrying the
RTS1-RFB were grown in the synthetic complete media EMMGlutamate. The RFB was maintained inactive (RFB OFF) in the presence of $60 \mu \mathrm{M}$ of thiamine in the medium. Activation of the RTS1RFB (RFB ON) was achieved by removing thiamine from the medium and growing cells for $24 \mathrm{~h}$. Sensitivity to genotoxic drugs was performed by spotting cells on media containing the appropriate drug.

\section{SSA assay}

We used the SSA method for S. pombe cells described (Watson et al, 2011). Cells cultures were grown in liquid $P M G+$ Leu medium at $30^{\circ} \mathrm{C}$ to logarithmic phase. Then, the cells were washed and resuspended at $5 \times 10^{6}$ cells $/ \mathrm{ml}$ in PMG+Leu+His medium with Ura (to induce DSB) or without Ura (as non-DSB induced control). The cells were incubated at $30^{\circ} \mathrm{C}$ for $5 \mathrm{~h}$. Immediately after this, the cells were counted and plated at 200-600 cells on PMG+Leu+His agar plates followed by incubation at $30^{\circ} \mathrm{C}$ for $5 \mathrm{~d}$ (fft1 $\Delta$, fft2 $\Delta$ ) or $7 \mathrm{~d}(\mathrm{fft} 3 \Delta)$ to recover and form colonies. Next, auxotrophy was tested as the plates were replica-printed onto $\mathrm{PMG}+\mathrm{His}$ and $\mathrm{PMG}+\mathrm{Leu}$ plates and incubated for another $2 \mathrm{~d}$ at $30^{\circ} \mathrm{C}$. Finally, colonies were scored for growth on the different plates. Colonies relying on added Leu, but not His, for growth were scored as parental (no DSB induced or repaired without error), colonies requiring added His, but not Leu, were scored as "efficient SSA," and colonies requiring both added His and Leu were designated "other." The few colonies $(<10)$ not needing either added His or Leu were not considered further. Colony numbers with parental phenotype $\left(\mathrm{his}^{+} \mathrm{leu}^{-}\right)$from the nonDSB induced control (without Ura) were used to determine the plating efficiency and the percentage of completed DNA repair. Also, non-DSB induced colonies with SSA phenotype (His ${ }^{-} \mathrm{Leu}^{+}$) were subtracted to account for "leakiness" of the urg1-system.

\section{qPCR}

DNA was isolated and GPCR was performed with SYBR Master mix (Life technology) using the Applied Biosystems 7500 RT-PCR System. The primer sequences for the SSA product, covering the LEU2 locus were forward: 5' GTG TTA GAC CTG AAC AAG GTT TAC, reverse: 5' GCA AAG AGG CCA AGG ACG.

\section{DSB assay}

The strains Hu2694 (WT), Hu2696 (fft2A), Hu2744 (fft3A), and Hu2745 (fft3 $\Delta$ ) were grown in liquid PMG+Leu medium, shaking overnight at $30^{\circ} \mathrm{C}$, to the mid logarithmic phase $(\mathrm{OD} 600=0,5)$. The cells were washed with fresh PMG+Leu medium and resuspended at a concentration of five million cells per $\mathrm{ml}$ in $\mathrm{PMG}+\mathrm{Leu}+\mathrm{H}$ is medium with Ura (to induce DSB) or without Ura (noninduced DSB control). The cells were incubated at $30^{\circ} \mathrm{C}$ for $5 \mathrm{~h}$, and samples of $1 \mathrm{ml}$ were taken at $0,1,2,3$, and $5 \mathrm{~h}$ followed by genomic DNA purification using the Thermo Fisher Scientific Yeast DNA Extraction Kit (Cat. no. 78870). qPCR was performed with purified genomic DNAs and primers to his3-HO and act1+ genomic regions. The primer sequences for the his3-HO locus were forward: GATACAGTTCTCACATCACATCCG, reverse: CAGCGATAAGGCTGAAGTTCTAAG. The primer sequences for the his3-HO locus were forward: TCCAACCGTGAGAAGATGAC, reverse: TGTGGGTAACACCATCACCA. Upon DSB induction, cycling time values 
Life Science Alliance

Table 1. List of S. pombe strains.

\begin{tabular}{|c|c|c|}
\hline Strain name & Genotype & Source \\
\hline Hu0029 & h- ade6-M210 leu1-32 ura4-D18 & Ekwall and Thon (2017) \\
\hline Hu1309 & $h+f f t 3:: k a n M X$ ade6-M210 leu1-32 ura4-DS/E & This study \\
\hline Hu1673 & h- fft2:: kanMX ade6-M210 leu1-32 ura4-D18 & This study \\
\hline Hu2656 & h- ade6-M210 leu1-32 ura4-D18 fft1::KANMX & This study \\
\hline Hu2694 & $\begin{array}{l}\text { h- urg1::Purg1lox-HgD LEU-HOcs-his3-lambda-EU2, leu1-32 } \\
\text { his3-D1 }\end{array}$ & This study \\
\hline Hu2695 & $\begin{array}{l}\text { h- urg1::Purg1lox-HgD LEU-HOcs-his3-lambda-EU2, leu1-32 } \\
\text { his3-D1 fft1::KANMX }\end{array}$ & This study \\
\hline Hu2696 & $\begin{array}{l}\text { h- urg1::Purg1lox-HgD LEU-HOcs-his3-lambda-EU2, leu1-32 } \\
\text { his3-D1 fft2::KANMX }\end{array}$ & This study \\
\hline Hu2697 & $\begin{array}{l}\text { h- urg1::Purg1lox-HgD LEU-HOcs-his3-lambda-EU2, } \\
\text { leu1-32 his3-D1 fft3::KANMX }\end{array}$ & This study \\
\hline Hu2744 & $\begin{array}{l}\text { h- urg1::Purg1lox-HgD LEU-HOcs-his3-lambda-EU2, } \\
\text { leu1-32 his3-D1 fft3::KANMX }\end{array}$ & This study \\
\hline Hu2745 & $\begin{array}{l}\text { h- urg1::Purg1lox-HgD LEU-HOcs-his3-lambda-EU2, } \\
\text { leu1-32 his3-D1 fft3::KANMX }\end{array}$ & This study \\
\hline Hu2698 & $\begin{array}{l}\text { h- urg1::Purg1lox-HgD LEU-HOcs-his3-lambda-EU2, } \\
\text { leu1-32 his3-D1 exo1::KANMX }\end{array}$ & This study \\
\hline YC6 & h- rtf1:nmt41:sup35 ade6-704 leu1-32 t-ura4sd20-ori & Iraqui et al (2012) \\
\hline YC13 & h- rtf1:nmt41:sup35 ade6-704 leu1-32 t-ura4sd20<ori & Iraqui et al (2012) \\
\hline YC21 & h- rtf1:nmt41:sup35 ade6-704 leu1-32 t<ura4sd20-ori & Iraqui et al (2012) \\
\hline YC281 & $\begin{array}{l}\text { h- fft3:: HYGMX rtf1:nmt41:sup35 ade6-704 leu1-32 } \\
\text { t-ura4sd20<ori }\end{array}$ & This study \\
\hline YC292 & h- fft3:: HYGMX rtf1:nmt41:sup35 ade6-704 leu1-32 t<ura4sd20-ori & This study \\
\hline YC280 & h-fft3:: HYGMX rtf1:nmt41:sup35 ade6-704 leu1-32 t-ura4sd20-ori & This study \\
\hline YC287 & $\begin{array}{l}h+f f t 2:: K A N M X \text { rtf1:nmt41:sup35 ade6-704 leu1-32 } \\
\text { t-ura4sd20<ori }\end{array}$ & This study \\
\hline YC294 & h+fft2:: KANMX rtf1:nmt41:sup35 ade6-704 leu1-32 t<ura4sd20-ori & This study \\
\hline YC284 & h-fft2:: KANMX rtf1:nmt41:sup35 ade6-704 leu1-32 t-ura4sd20-ori & This study \\
\hline YC309 & $\begin{array}{l}\text { h- fft3-myc:HYGMX rtf1:nmt41:sup35 ade6-704 leu1-32 } \\
\text { t-ura4sd20<ori }\end{array}$ & This study \\
\hline YC317 & $\begin{array}{l}\text { h- fft3-myc:HYGMX rtf1:nmt41:sup35 ade6-704 leu1-32 } \\
\text { t<ura4sd20-ori }\end{array}$ & This study \\
\hline YC321 & $\begin{array}{l}\text { h- fft3-myc:HYGMX rtf1:nmt41:sup35 ade6-704 leu1-32 } \\
\text { t-ura4sd20-ori }\end{array}$ & This study \\
\hline YC313 & $\begin{array}{l}\text { h- fft3-K418R-myc:HYGMX rtf1:nmt41:sup35 ade6-704 leu1-32 } \\
\text { t-ura4sd20<ori }\end{array}$ & This study \\
\hline YC325 & $\begin{array}{l}\text { h-fft3K418R-myc:HYGMX rtf1:nmt41:sup35 ade6-704 leu1-32 } \\
\text { t<ura4sd20-ori }\end{array}$ & This study \\
\hline YC329 & $\begin{array}{l}\text { h-fft3K418R-myc:HYGMX rtf1:nmt41:sup35 ade6-704 leu1-32 } \\
\text { t-ura4sd20-ori }\end{array}$ & This study \\
\hline KK851 & $\begin{array}{l}\text { ssb3-YFP:NATMX rtf1:nmt41:sup35 t-ura4sd20<ori ade6-704 } \\
\text { leu1-32 }\end{array}$ & This study \\
\hline KK854 & $\begin{array}{l}\text { fft3:: HYGMX ssb3-YFP:NATMX rtf1:nmt41:sup35 t-ura4sd20<ori } \\
\text { ade6-704 leu1-32 }\end{array}$ & This study \\
\hline KK857 & $\begin{array}{l}\text { fft3K418R-myc:HYGMX ssb3-YFP:NAT rtf1:nmt41:sup35 } \\
\text { t-ura4sd20<ori ade6-704 leu1-32 }\end{array}$ & This study \\
\hline KK860 & $\begin{array}{l}\text { fft3-myc:HYGMX ssb3-YFP:NAT rtf1:nmt41:sup35 t-ura4sd20<ori } \\
\text { ade6-704 leu1-32 }\end{array}$ & This study \\
\hline
\end{tabular}


for his3-HO region were increased because of DSB generation and subsequent loss of intact template for amplification compared with act1+ gene sequence where no DSBs are normally generated. Therefore, the qPCR allowed us to measure DSB at his3-HO relative to act1+. Difference in cycling time $(\triangle C T)$ values were determined as CT(his3-HO) - CT(act1) and fold changes were calculated as (average $\mathrm{E}$ ) to the power of $\Delta \mathrm{CT}$. Then, fold change differences were converted into percentages, given that $\Delta C T=0$ would represent $0 \%$ of DSB induction, and the maximal fold change difference value obtained was set as $100 \%$ of DSB induction. This approach allowed us to represent relative levels of DSB induction in the cells. Fold change values were used to calculate averages, SD and SEM values, and input data for statistical significance testing ( $t$ test).

\section{Analysis of replication intermediates by 2DGE}

Replication intermediates were analyzed by 2DGE as described by Ait Saada et al (2017). $2.5 \times 10^{9}$ exponentially growing cells were harvested with $0.1 \%$ sodium azide and frozen EDTA ( $80 \mathrm{mM}$ final concentration). The cells were cross-linked by adding trimethylpsoralen (0.01 mg/ml, TMP, 3902-71-4; Sigma-Aldrich) to the cell suspensions, for $5 \mathrm{~min}$ in the dark. The cells were then exposed to UV-A $(365 \mathrm{~nm})$ for $90 \mathrm{~s}$ at a flow of $50 \mathrm{~mW} / \mathrm{cm}^{2}$. The cells were lysed with $0.625 \mathrm{mg} / \mathrm{ml}$ lysing enzyme (L1412; Sigma-Aldrich) and $0.5 \mathrm{mg} /$ $\mathrm{ml}$ zymolyase 100T (120493-1; Amsbio) for $15 \mathrm{~min}$ at $37^{\circ} \mathrm{C}$. Spheroplasts were then embedded into $1 \%$ low-melting agarose (InCert Agarose, Lonza) plugs and incubated overnight at $55^{\circ} \mathrm{C}$ in a digestion buffer containing $1 \mathrm{mg} / \mathrm{ml}$ of proteinase $\mathrm{K}$ (EU0090; Euromedex) and then washed and stored in TE (50 mM Tris and 10 mM EDTA) at $4^{\circ} \mathrm{C}$. DNA digestion was performed with 30 units per plug of the restriction enzyme Asel and equilibrated at $0.3 \mathrm{M} \mathrm{NaCl}$. Replication intermediates were enriched using BND cellulose columns (B6385; Sigma-Aldrich) as described in Lambert et al (2010). Purified replication intermediates were then separated by bidimensional gel electrophoresis (0.35\% agarose gel in TBE for the first dimension, $0.9 \%$ agarose gel-TBE supplemented with EtBr at 0.3 $\mu \mathrm{g} / \mathrm{ml}$ ). DNA was transferred to a nylon membrane in $10 \times \mathrm{SSC}$. Membranes were incubated with a ${ }^{32} \mathrm{P}$ radio-labeled ura 4 probe, an RIs were detected using Phosphorimager software (Typhoon Trio) and quantified with ImageQuant TL.

\section{Chromatin immunoprecipitation of $\mathrm{Fft} 3$}

DNA was immunoprecipitated as described earlier (Durand-Dubief \& Ekwall, 2009) with following changes. Strains carrying the RTS1RFB were cultured in supplemented EMMG media containing $60 \mu \mathrm{M}$ thiamine. The cells were washed twice with water to remove thiamine and released into EMMG, either without (Rtf1 induced, RBF ON) or with (Rtf1 repressed, RBF OFF) $60 \mu \mathrm{M}$ thiamine. After 24-25 h of RFB induction, $2 \times 10^{8}$ cells were fixed in $1 \%$ formaldehyde (252549; Sigma-Aldrich) for $30 \mathrm{~min}$ at room temperature with gentle agitation (Infors Multitron shaker; e120 rpm). To quench the crosslinking reaction, glycine was added to a final concentration of 125 mM. After 5-min incubation (RT, $120 \mathrm{rpm}$ ), the cells were collected by centrifugation $\left(900 \mathrm{~g}, 10 \mathrm{~min}, 4^{\circ} \mathrm{C}\right.$ ), washed twice with $25 \mathrm{ml}$ of icecold PBS, and snap-frozen. The cells were resuspended in $400 \mu \mathrm{l}$ of cold CHIP lysis buffer CLB (50 mM Hepes-KOH, pH 7.5, $150 \mathrm{mM} \mathrm{NaCl}$, 0.1\% SDS, $1 \%$ Triton $\mathrm{X}-100,0.1 \%$ sodium deoxycholate, $1 \mathrm{mM}$ EDTA, and protease inhibitors [Complete Protease Inhibitor Cocktail EDTA-free, 11873580001; Roche]), transferred to the prechilled 2-ml skirted tube, containing $500 \mu \mathrm{l}$ of zirconia/silica beads (11079105z; BioSpec products), and disrupted in a FastPrep-24 machine (116004500; MP Biomedicals) for two cycles (rate 6.5, $30 \mathrm{~s}$ on; 2 min off, $4^{\circ} \mathrm{C}$ ). The crude lysates were sonicated (Bioruptor pico; Diagenode) for three cycles (30 s on; $60 \mathrm{~s}$ off, $4^{\circ} \mathrm{C}$ ) and clarified by centrifugation $\left(16,000 \mathrm{~g}, 4^{\circ} \mathrm{C}, 10 \mathrm{~min}\right)$. The clarified chromatin extracts were transferred into fresh tubes. $5 \mu \mathrm{l}$ of each chromatin extract was saved as input samples for subsequent quantification of the DNA enrichment. For each ChIP reaction, $100 \mu$ lof the extract was diluted with nine volumes of Binding Buffer B1 (as CLB, no SDS) to reduce SDS to a final concentration of $0.01 \%$, with BSA added to $0.1 \%$ final concentration. The chromatin was immunoprecipitated using $2 \mu \mathrm{g}$ of anti-Myc antibody (05-724, Upstate) for $2 \mathrm{~h}$ at $4^{\circ} \mathrm{C}$, followed by incubation with $20 \mu \mathrm{l}$ of pre-equilibrated Protein $\mathrm{A} / \mathrm{G}$ magnetic beads (88802; Thermo Fisher Scientific) for $1 \mathrm{~h}$. A sample without added antibody was prepared to assess unspecific DNA binding to the beads (later referred as no antibody [no ab] control sample). In addition, a parallel ChIP experiment was performed in the WT strain, lacking epitope tag, to evaluate efficiency and specificity of the anti-Myc antibody.

Beads were washed with $2 \times 500 \mu \mathrm{l}$ of cold B1 buffer, $1 \times 500 \mu \mathrm{l} \mathrm{B1/}$ $500 \mathrm{mM} \mathrm{NaCl}, 1 \times 500 \mu \mathrm{l} \mathrm{B2}(10 \mathrm{mM}$ Tris-Cl, pH 7.5, $250 \mathrm{mM} \mathrm{LiCl}, 1 \mathrm{mM}$ EDTA, 0.5\% Na-deoxycholate, and 0.5\% IGEPAL-630) and resuspended in $350 \mu \mathrm{l}$ of TE (10 mM Tris-CL, pH 8, and $1 \mathrm{mM}$ EDTA). The samples were transferred to fresh tubes, TE was removed, and 100 $\mu \mathrm{l}$ of TE, containing $0.1 \mu \mathrm{g} / \mu \mathrm{l}$ of RNaseA (10109169001; Roche), was added to each tube. The samples were incubated for $15 \mathrm{~min}$ at $37^{\circ} \mathrm{C}$, treated with $0.5 \mu \mathrm{g} / \mu$ l of Proteinase K (03 115801 001; Roche) in 0.5\% SDS for $1 \mathrm{~h}$ at $42^{\circ} \mathrm{C}$, and subsequently incubated at $65^{\circ} \mathrm{C}$ overnight to reverse crosslinks. The input samples were mixed with $45 \mu \mathrm{l} \mathrm{of} \mathrm{TE}$ containing RNaseA $(0.2 \mu \mathrm{g} / \mu \mathrm{l})$ and processed identically to the IP samples and the no ab samples.

The immunoprecipitated DNA was isolated using QIAquick PCR purification kit (28106; QIAGEN) according to the manufacturer's instructions. The DNA was eluted in $40 \mu$ l of elution buffer. For qPCR analysis, FastStart Universal SYBR Green Master (04 913914 001; Roche) was used. $2 \mu \mathrm{l}$ of the immunoprecipitated DNA were used as a template in total reaction volume of $12 \mu \mathrm{l}$. Gene-specific primers were used at a final concentration of $400 \mathrm{nM}$. The DNA quantity in the IP and input samples was determined using a standard curve method. The enrichment of the immunoprecipitated DNA was calculated relatively to the appurtenant input sample and presented as the percent of input DNA.

\section{Chromatin immunoprecipitation of RPA}

Chromatin immunoprecipitation against RPA (ssb3-YFP) was performed as described in (Tsang et al, 2014) with following modifications. $200 \mathrm{ml}$ of logarithmic culture (total of $2 \times 10^{9}$ cells) for each condition (RTS1-RFB OFF/ON) was divided into $2 \times 100 \mathrm{ml}$ aliquots and cross-linked with $10 \mathrm{mM}$ dimethyl adipimidate (285625; SigmaAldrich) for 45 min and subsequently with $1 \%$ formaldehyde (F-8775; Sigma-Aldrich) for $15 \mathrm{~min}$. Next, the cells from each 100-ml aliquot 
Table 2. List of primers used for RPA ChIP-qPCR.

\begin{tabular}{|c|c|c|}
\hline Name & $\begin{array}{l}\text { Distance (bp) from the } \\
\text { RTS1-RFB position }\end{array}$ & Sequence $\left(5^{\prime}-3^{\prime}\right)$ \\
\hline L5F & \multirow{2}{*}{-110} & AGGGCATTAAGGCTTATTTACAGA \\
\hline L5R & & TCACGTTTAATTTCAAACATCCA \\
\hline L3F & \multirow{2}{*}{110} & TTTAAATCAAATCTTCCATGCG \\
\hline L3R & & TGTACCCATGAGCAAACTGC \\
\hline L400F & \multirow{2}{*}{450} & ATCTGACATGGCATTCCTCA \\
\hline L400R & & GATGCCAGACCGTAATGACA \\
\hline L600F & \multirow{2}{*}{600} & CCATTGACTAGGAGGACTTTGAG \\
\hline L600R & & СCCTGGCGGTTGTAGTTAGT \\
\hline L900F & \multirow{2}{*}{900} & AACGGTTGTAGAAGACGAGCA \\
\hline L900R & & TGTAAGCACACCTTCAATGTATCA \\
\hline L1400F & \multirow{2}{*}{1,400} & AACATCGGTGACCTCGTTCT \\
\hline L1400R & & СTCTTCGCTCCAAGCGTTAT \\
\hline $1150 \mathrm{~F}$ & \multirow{2}{*}{ Control locus on Chrll } & CACCGCAGTTCTACGTATCCT \\
\hline II50R & & CGATGTAACGGTATGCGGTA \\
\hline
\end{tabular}

were frozen in liquid nitrogen and lysed by bead beating in $400 \mu \mathrm{l}$ of lysis buffer (50 mM Hepes, pH 7.5, 1\% Triton X-100, 0.1\% Nadeoxycholate, $1 \mathrm{mM}$ EDTA) with $1 \mathrm{mM}$ PMSF, and complete EDTAfree protease inhibitor cocktail tablets (1873580; Roche). Chromatin sonication was performed using a Diagenode Bioruptor in a mode High, 10 cycles of $30 \mathrm{~s}$ ON and $30 \mathrm{~s}$ OFF in ice-cold water. Then sonicated chromatin fractions from each sample were pooled (400 $+400 \mu \mathrm{l}$ ), and immunoprecipitation overnight was performed as follows: $300 \mu \mathrm{l}$ was incubated with anti-GFP antibody (A11122; Invitrogen) at 1:150 concentration, $300 \mu$ l was incubated with Normal Rabbit IgG antibody (\#2729S; Cell Signaling Technology) at concentration 1:75 and $5 \mu \mathrm{l}$ was preserved as an INPUT fraction. Next day, Protein G Dynabeads (10003D; Invitrogen) were added for $1 \mathrm{~h}$ and immunoprecipitated complexes and preserved INPUTs were de-cross-linked for $2 \mathrm{~h}$ at $65^{\circ} \mathrm{C}$. DNA was purified with a QIAquick PCR purification kit (28104; QIAGEN) and eluted in $400 \mu$ l of water. qPCR (iQ SYBR Green Supermix, 1708882; Bio-Rad, primers listed in Table 2) was performed to determine the relative amounts of DNA (starting quantities based on standard curves for each pair of primers). RPA enrichment was calculated by dividing IP by INPUT values for specific (GFP) and unspecific (IgG) antibodies. Next, the values for unspecific IgG were subtracted and subsequently specific GFP signal was normalized over an internal control locus at chromosome II (II.50). The RPA enrichment was presented as ratio RTS1-RFB ON/OFF conditions.

\section{RS assay with ura4-sd20 allele}

RS using the ura4-sd20 allele was performed as previously described (Iraqui et al, 2012). Ura+ cells were first counter-selected on 5-FOA plate. Single 5-FOA-resistant colonies were grown on uracilcontaining plates with or without thiamine for $2 \mathrm{~d}$ at $30^{\circ} \mathrm{C}$ and then inoculated in uracil-containing EMM for $24 \mathrm{~h}$. The cells were diluted and plated on YE plates (for survival counting) and on uracil-free plates containing thiamine to determine the reversion frequency. Colonies were counted after $5-7 \mathrm{~d}$ of incubation at $30^{\circ} \mathrm{C}$. Statistics were performed using $t$ test.

\section{Supplementary Information}

Supplementary Information is available at https://doi.org/10.26508/lsa. 201900433

\section{Acknowledgements}

Work in the K Ekwall laboratory was supported by grants from the Swedish Cancer Society (Cancerfonden) and the Swedish Research Council (Vetenskapsrådet). Work in the S Lambert laboratory was supported by grants from the Fondation pour la Recherche Médicale "Equipe Fondation pour la Recherche Médicale DEQ20160334889," the Fondation ARC (l'Association pour la Recherche sur le Cancer), and the Ligue (comité Essone). A Ait-Saada was funded by the Fondation ARC.

\section{Author Contributions}

A Ait-Saada: investigation and writing-review and editing.

O Khorosjutina: formal analysis, investigation, and writing-review and editing.

J Chen: investigation and writing-review and editing.

K Kramarz: investigation.

$\checkmark$ Maksimov: investigation and writing-review and editing.

JP Svensson: conceptualization, formal analysis, and writing-review and editing.

S Lambert: conceptualization, supervision, funding acquisition, and writing-original draft, review, and editing.

K Ekwall: conceptualization, supervision, funding acquisition, and writing-original draft, review, and editing.

\section{Conflict of Interest Statement}

The authors declare that they have no conflict of interest.

\section{References}

Adkins NL, Swygert SG, Kaur P, Niu H, Grigoryev SA, Sung P, Wang H, Peterson CL (2017) Nucleosome-like, single-stranded DNA (ssDNA)-histone octamer complexes and the implication for DNA double strand break repair. J Biol Chem 292: 5271-5281. doi:10.1074/jbc.M117.776369

Ait Saada A, Teixeira-Silva A, Iraqui I, Costes A, Hardy J, Paoletti G, Freon K, Lambert SAE (2017) Unprotected replication forks are converted into mitotic sister chromatid bridges. Mol Cell 66: 398-410.e4. doi:10.1016/ j.molcel.2017.04.002

Allshire RC, Ekwall K (2015) Epigenetic regulation of chromatin states in Schizosaccharomyces pombe. Cold Spring Harb Perspect Biol 7: a018770. doi:10.1101/cshperspect.a018770

Bantele SC, Ferreira P, Gritenaite D, Boos D, Pfander B (2017) Targeting of the Fun30 nucleosome remodeller by the Dpb11 scaffold facilitates cell cycle-regulated DNA end resection. Elife 6: e21687. doi:10.7554/ elife.21687 
Bi X, Yu Q, Siler J, Li C, Khan A (2015) Functions of Fun30 chromatin remodeler in regulating cellular resistance to genotoxic stress. PLoS One 10: e0121341. doi:10.1371/journal.pone.0121341

Chen X, Cui D, Papusha A, Zhang X, Chu CD, Tang J, Chen K, Pan X, Ira G (2012) The Fun30 nucleosome remodeller promotes resection of DNA double-strand break ends. Nature 489: 576-580. doi:10.1038/ nature11355

Costelloe T, Louge R, Tomimatsu N, Mukherjee B, Martini E, Khadaroo B, Dubois K, Wiegant WW, Thierry A, Burma S, et al (2012) The yeast Fun30 and human SMARCAD1 chromatin remodellers promote DNA end resection. Nature 489: 581-584. doi:10.1038/nature11353

Durand-Dubief M, Ekwall K (2009) Chromatin immunoprecipitation using microarrays. Methods Mol Biol 529: 279-295. doi:10.1007/978-1-59745538-1_18

Eapen VV, Sugawara N, Tsabar M, Wu WH, Haber JE (2012) The Saccharomyces cerevisiae chromatin remodeler Fun30 regulates DNA end resection and checkpoint deactivation. Mol Cell Biol 32: 4727-4740. doi:10.1128/ MCB.00566-12

Ekwall K, Thon G (2017) Genetic analysis of Schizosaccharomyces pombe. Cold Spring Harb Protoc 2017: pdb.top079772. doi:10.1101/ pdb.top079772

Flaus A, Martin DM, Barton GJ, Owen-Hughes T (2006) Identification of multiple distinct Snf2 subfamilies with conserved structural motifs. Nucleic Acids Res 34: 2887-2905. doi:10.1093/nar/gkl295

Goellner EM, Putnam CD, Graham WJ 5th, Rahal CM, Li BZ, Kolodner RD (2018) Identification of Exo1-Msh2 interaction motifs in DNA mismatch repair and new Msh2-binding partners. Nat Struct Mol Biol 25: 650-659. doi:10.1038/s41594-018-0092-y

Iraqui I, Chekkal Y, Jmari N, Pietrobon V, Freon K, Costes A, Lambert SA (2012) Recovery of arrested replication forks by homologous recombination is error-prone. PLoS Genet 8: e1002976. doi:10.1371/ journal.pgen.1002976

Jacobs IZ, Rosado-Lugo JD, Cranz-Mileva S, Ciccaglione KM, Tournier V, Zaratiegui M (2015) Arrested replication forks guide retrotransposon integration. Science 349: 1549-1553. doi:10.1126/science.aaa3810

Jahn LJ, Mason B, Brogger P, Toteva T, Nielsen DK, Thon G (2018) Dependency of heterochromatin domains on replication factors. G3 8: 477-489. doi:10.1534/g3.117.300341

Lambert S, Mizuno K, Blaisonneau J, Martineau S, Chanet R, Freon K, Murray JM, Carr AM, Baldacci G (2010) Homologous recombination restarts blocked replication forks at the expense of genome rearrangements by template exchange. Mol Cell 39: 346-359. doi:10.1016/ j.molcel.2010.07.015

Lambert S, Watson A, Sheedy DM, Martin B, Carr AM (2005) Gross chromosomal rearrangements and elevated recombination at an inducible site-specific replication fork barrier. Cell 121: 689-702. doi:10.1016/j.cell.2005.03.022

Lee J, Choi ES, Seo HD, Kang K, Gilmore JM, Florens L, Washburn MP, Choe J, Workman JL, Lee D (2017) Chromatin remodeller Fun30Fft3 induces nucleosome disassembly to facilitate RNA polymerase II elongation. Nat Commun 8: 14527. doi:10.1038/ncomms14527

Miyabe I, Mizuno K, Keszthelyi A, Daigaku Y, Skouteri M, Mohebi S, Kunkel TA, Murray JM, Carr AM (2015) Polymerase delta replicates both strands after homologous recombination-dependent fork restart. Nat Struct Mol Biol 22: 932-938. doi:10.1038/nsmb.3100
Mizuno K, Miyabe I, Schalbetter SA, Carr AM, Murray JM (2013) Recombinationrestarted replication makes inverted chromosome fusions at inverted repeats. Nature 493: 246-249. doi:10.1038/nature11676

Persson J, Steglich B, Smialowska A, Boyd M, Bornholdt J, Andersson R, Schurra C, Arcangioli B, Sandelin A, Nielsen O, et al (2016) Regulating retrotransposon activity through the use of alternative transcription start sites. EMBO Rep 17: 753-768. doi:10.15252/ embr.201541866

Petersen J, Russell P (2016) Growth and the environment of Schizosaccharomyces pombe. Cold Spring Harb Protoc 2016: pdb.top079764. doi:10.1101/pdb.top079764

Rayhan A, Faller A, Chevalier R, Mattice A, Karagiannis I (2018) Using genetic buffering relationships identified in fission yeast to reveal susceptibilities in cells lacking hamartin or tuberin function. Biol Open 7: bio031302. doi:10.1242/bio.031302

Steglich B, Stralfors A, Khorosjutina O, Persson J, Smialowska A, Javerzat JP Ekwall K (2015) The Fun30 chromatin remodeler Fft3 controls nuclear organization and chromatin structure of insulators and subtelomeres in fission yeast. PLoS Genet 11: e1005101. doi:10.1371/ journal.pgen.1005101

Storey AJ, Wang HP, Protacio RU, Davidson MK, Tackett AJ, Wahls WP (2018) Chromatin-mediated regulators of meiotic recombination revealed by proteomics of a recombination hotspot. Epigenetics Chromatin 11: 64. doi:10.1186/s13072-018-0233-x

Stralfors A, Walfridsson J, Bhuiyan H, Ekwall K (2011) The FUN30 chromatin remodeler, Fft3, protects centromeric and subtelomeric domains from euchromatin formation. PLOS Genet 7: e1001334. doi:10.1371/ journal.pgen.1001334

Taneja N, Zofall M, Balachandran V, Thillainadesan G, Sugiyama T, Wheeler D, Zhou M, Grewal SI (2017) SNF2 family protein Fft3 suppresses nucleosome turnover to promote epigenetic inheritance and proper replication. Mol Cell 66: 50-62.e6. doi:10.1016/ j.molcel.2017.02.006

Teixeira-Silva A, Ait Saada A, Hardy J, Iraqui I, Nocente MC, Freon K, Lambert SAE (2017) The end-joining factor Ku acts in the end-resection of double strand break-free arrested replication forks. Nat Commun 8: 1982. doi:10.1038/s41467-017-02144-5

Terui R, Nagao K, Kawasoe Y, Taki K, Higashi TL, Tanaka S, Nakagawa T, Obuse C, Masukata H, Takahashi TS (2018) Nucleosomes around a mismatched base pair are excluded via an Msh2-dependent reaction with the aid of SNF2 family ATPase Smarcad1. Genes Dev 32: 806-821. doi:10.1101/gad.310995.117

Tsang E, Miyabe I, Iraqui I, Zheng J, Lambert SA, Carr AM (2014) The extent of error-prone replication restart by homologous recombination is controlled by Exo1 and checkpoint proteins. J Cell Sci 127: 2983-2994. doi:10.1242/jcs.152678

Watson AT, Werler P, Carr AM (2011) Regulation of gene expression at the fission yeast Schizosaccharomyces pombe urg1 locus. Gene 484: 75-85. doi:10.1016/j.gene.2011.05.028

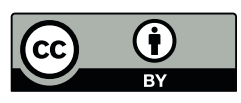

License: This article is available under a Creative Commons License (Attribution 4.0 International, as described at https://creativecommons.org/ licenses/by/4.0/). 